\title{
INJURY PROFILE OF NON-CONTACT SPORTS FOR PERAK SUKMA ATHLETES
}

\author{
A. C. Lee ${ }^{*}$ M. Sankaravel, S. Mondam and P. F. Kuang \\ Faculty of Sports Science and Coaching, Universiti Pendidikan Sultan Idris, Tg Malim, Perak, \\ Malaysia
}

Published online: 10 November 2017

\begin{abstract}
The purpose of this study is to identify the injury profile of non-contact sports among Perak SUKMA athletes. The data from this injury is examined based on the five research questions which are nature of injury, body part, severity of injury (mild, moderate, severe), types of injury (acute or chronic), and factors of injury. The descriptive statistics was utilized to analyze the research variables. The results showed that subsequent injury (57.8\%) more than new injury (42.2\%) while the incidence of injuries happened more in lower limb (51.1\%). The severity of injuries can be seen more in moderate injury with $73.3 \%$. Chronic injury $(71.9 \%)$ was reported more than the acute injury (28.1\%). Lastly, the finding revealed that self induce $(46.7 \%)$ is the main factor contributin injuries. In conclusion, supervision and monitoring athletes during training is essential by all the sports community to minize the risk of injury.
\end{abstract}

Keywords: epidemiology; non-contact sports; Perak SUKMA athletes; non-contact sports injuries; acute and chronic injuries.

Author Correspondence, e-mail: lee.ac@fsskj.upsi.edu.my

doi: http://dx.doi.org/10.4314/jfas.v9i6s.84 


\section{INTRODUCTION}

A number of studies recorded that athlete from wide range of sports areas, who involved in sports more than a year, facing high risk for the injuries. Sports participation at higher level also related to increase the rate of injury [1]. Research found that each different sport will represent specific injury patterns regarding the type, nature and frequency of injuries.

In worldwide, sports are divided into three different groups consists of contact sports, non-contact sports and collision sports. The definition from the medical dictionary stated that contact sports are the sports in which the players have a range of contact with either other or with inanimate objects. The examples of contact sports included rugby, diving, wrestling, and so on. The non-contact sport is defined as the sports in which the players are physically separated such as to make it nearly impossible for them to make physical contact during the course of the game. The non-contact sports such as tennis, badminton, volleyball, netball, squash and so on are basically low intensity and static demand. The collision sport is the sports which the players will purposely hit or collide with each other or inanimate objects, including the ground with great force. The actions include tackling, body checking, blocking and so on. Whenever there are any training or competition, there will be injuries happened to the athletes no matter how is the mechanism of injuries. Most of the sports either contact, non-contact or collision sports, injuries may occur. One cannot simply believe that sports without any physical contact will not cause injuries. Thus, this study was conducted to determine the incidence of sports injuries in non-contact sports, also to identify risk factors and time loss due to injuries.

\section{METHODOLOGY}

\subsection{Research Design}

This research is a retrospective descriptive epidemiological study that involved the Perak SUKMA athletes who participated in non-contact sports. The purpose of selecting this research design is to verify the current injury profile of non-contact sports injuries among Perak SUKMA athletes in review between various sports, types of sports, types of injury, body location of injury, injury severity and nature of injury. The data was collected at Perak Sport State Council, Ipoh. 


\subsection{Population and Sampling}

There were 405 Perak SUKMA non-contact sports athletes' medical records were referred as data. Only 135 athletes reported injured due to non-contact sports such as swimming, diving, weightlifting, badminton, cycling, gymnastic artistic, lawn bowls, archery, shooting, athletics, sailing, sepak takraw, squash, bowling, wushu, indoor volleyball, beach volleyball, golf, petanque and tennis.

\subsection{Research Instrument}

The research instrument used in this study was a questionnaire to screen and to record the medical records obtained from Perak Sport State Council, Ipoh. There was no standardized documentation used in Perak Sport State Council by the medical doctor for the injured athletes. A data collection form was utilized in order to make sure the research data was obtained correctly according to the medical records and research requirement. The specific information from the medical records included types of non-contact sports, types of injury, body location of injury, injury severity and nature of injury among Perak SUKMA athletes.

The questionnaire is divided into two sections: Section A and Section B. Section A consisted background information sheet which contains personal information such as athlete's gender, age, type of sports involved, period of participation, and the age of initial exposure. Section B is regarding the injuries profile such as types of injury, body location of injury, injury severity and nature of injury among Perak SUKMA athletes.

\subsection{Data Analysis}

The descriptive statistical i.e mean and frequency were used to report the demographic data, and the independent variables in this study. Data was analysed using Statistical Package for Social Sciences 21.0 (SPSS) for Windows. The significance level of this study was predetermined at $0.05(\mathrm{p}<0.05)$.

\section{RESULTS AND DISCUSSION}

\subsection{Nature of Injuries}

The result of the nature of injuries among Perak SUKMA athletes in non-contact sports showed that 78 injuries cases $(57.8 \%)$ reported as subsequent injury while new injury reported 57 injuries cases $(42.2 \%)$. Figure 1 showed the percentage distribution of the nature of 
injuries.

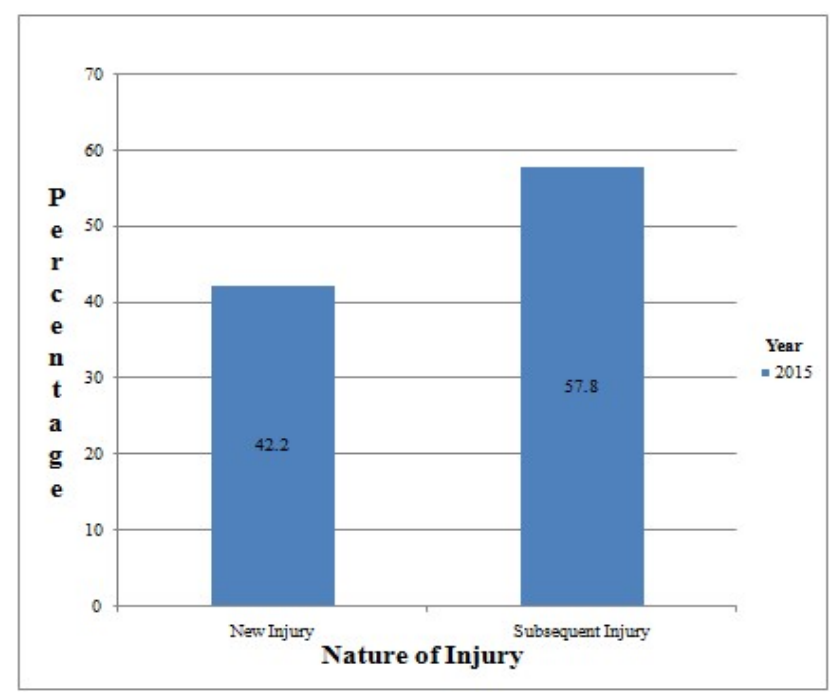

Fig.1. Percentage distribution of nature of injuries

The first research question in this study is to determine the nature of injury either new or subsequent injury that sustained by the Perak SUKMA athletes. Based on the previous studies, there was evidence proved that the nature of injury could possibly cause by subsequent injury and on the same location as the previous injury. This can be explained that the muscles of the injury site were weak and the ligaments become imbalance due to the previous injury. Thus, these could be the risk to reinjure in the future [2]. Undeniably, the highest number of subsequent injury was due to the athletes who sustained previous injury. These findings were supported previous study stated that athletes who sustained previous injury has the significant risk factor to be reinjure [3-5]. Moreover, athletes who had higher skill were at greater risk to get injured [6].

\subsection{Body Location of Injury}

Figure 2 revealed that the injured body part reported in this study indicated that lower limb experienced highest with $51.1 \%$ followed by upper limb $(25.9 \%)$, head/neck/spine columns $(12.6 \%)$, trunk (10.4\%) and no face/scalp injuries $(0 \%)$. 


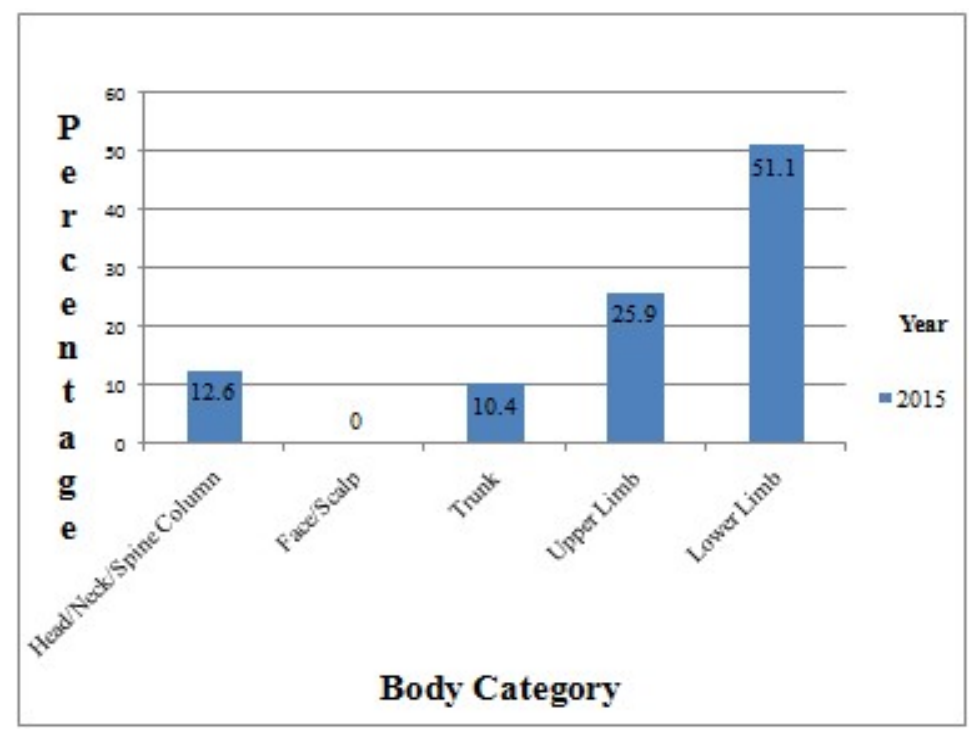

Fig.2. Percentage distribution of body location of injury

The second research question of this study is to find out the common injured body part of Perak SUKMA athletes. Mostly the injuries happened because of the excessive or repetitive force constraining to the connective tissues of the muscles and the bone. In early stages of injuries, pain will act as a notification for the injuries to remind the athletes to stop any vigorous activities. However, there were athletes ignored the pain and continue to train on pain killers. The ignorance indirectly gives pressure to the injured part. Consequently, the injured body part did not have sufficient time to heal, inversely were continuously damaged. Most of the research studies found that lower limb injury reported increasing every year [7-12]. The Scandinavian's study stated that sports injuries conquer $19 \%$ of all kinds of injuries, and knee and ankle injuries had the larger number of injury cases [12]. The study also found that high incidence of injury occurrence in lower limbs (59.9\%) compared with the upper extremity region (20.8\%). Injuries to the lower limb accounted for $59.5 \%$ of all reported injuries with the record of 188 cases [7]. Anterior cruciate ligament injuries were reported as the severe knee injuries among all knee injuries [12]. Any weight bearing sports that required the athletes to run, turn, change of direction and jump will often lead to lower extremities injury especially knee and ankle region [13]. The most common lower limb injuries can be seen to the area of ankle and knee which surrounding by many ligaments. These injuries normally take at least six months to heal and regain its normal strength ability. These injuries 
do not only reduced strength but also proprioception. Thus, the use of supportive gear is highly recommended to the athletes. Surve et al. revealed that the use of bracing is effective in preventing injuries especially to the athletes who had injury history [14]. Tsui and colleague stated that the upper extremity injury $(30 \%)$ was the second common injuries follower by lower extremity injuries (47\%) and head (24\%). Furthermore, the study on adolescent squash revealed that thigh region is frequently injured location which accounting $19 \%$ against the shoulder region (13\%) and lower back area (13\%) [15].

\subsection{Types of Injury}

The study finding indicated that acute injuries obtained 38 cases (28.1\%) and chronic injuries revealed 97 cases i.e $71.9 \%$. Figure 3 showed that the percentage distributions as types of injury either acute or chronic injuries.

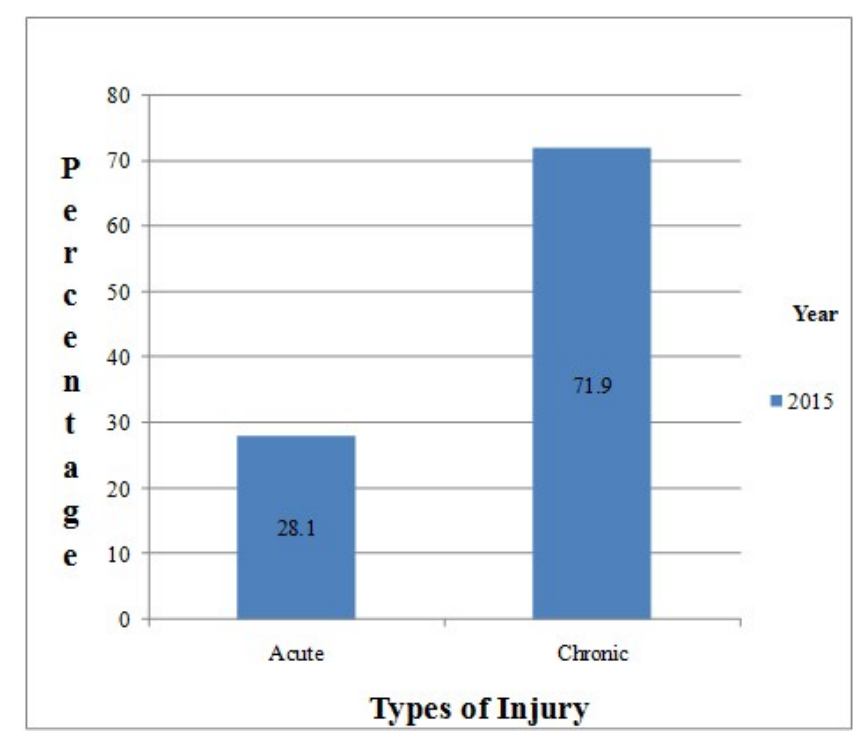

Fig.3. Percentage distribution of types of injury

As everyone knew, various types of sports may have different types of injury. A variety of sports such as soccer, rugby, gymnastics are mostly prone to acute injuries while cross-country and racquet sports are more prone to chronic repetitive or overuse injuries [16]. Thus, this current study found that chronic injuries were commonly occurred among the Perak SUKMA athletes involved in non-contact sports. This can be explained by previous study that increasing of overuse injuries is mainly due to the indirect implication of the types of training program [17]. The weekly intense schedule in sports competition and long training time were 
the reasons of overuse injury. This is because the excessive training and competition did not permit athletes to recover from fatigue and return to play with their optimum performance [18].

\subsection{Injury Severity}

In addition, the study finding regarding injury severity showed that Perak SUKMA athletes in non-contact sports obtained more moderate injury (73.3\%) compared to mild injury and severe injury (14.8\% and $11.9 \%$ respectively).

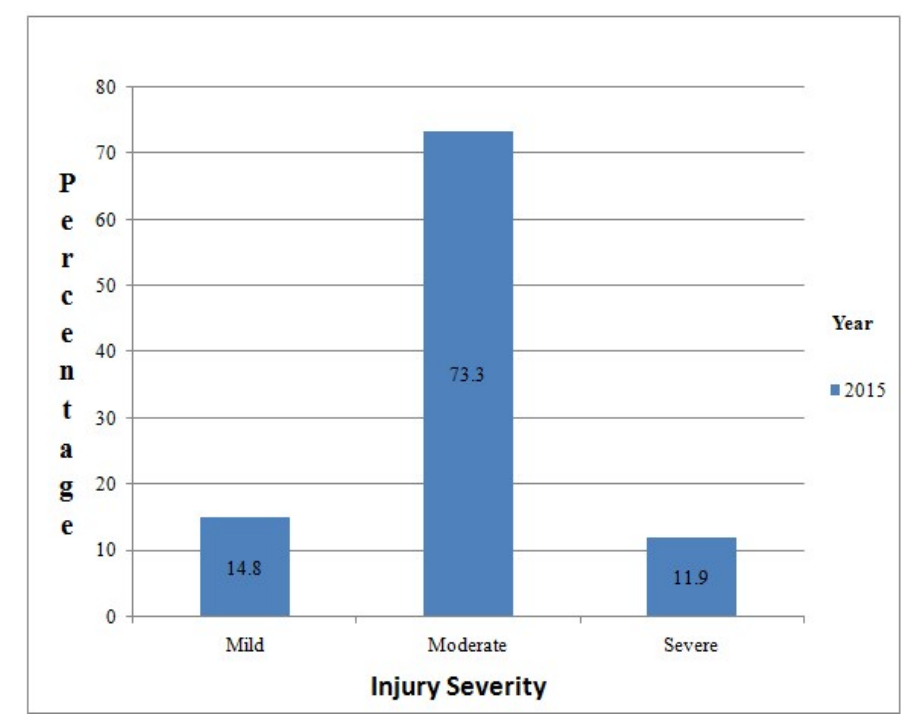

Fig.4. Percentage distribution of severity of injury

The most common types of injury reported were contusion, sprains, and strain. Adversely, the severe injuries such as fracture, dislocations, rupture of ligaments and so on are not much seen during sports [19-20]. The findings of previous studies supported that present study finding signified that more than half of the injuries reported were moderate injuries $(65.2 \%)$ followed by mild injuries $(26.7 \%)$ and severe injuries $(8.1 \%)$.

\subsection{Factors of Injury}

Figure 5 showed that the percentage distribution of the risk factors contributed to injuries obtained by Perak SUKMA athletes involved in non-contact sports. 


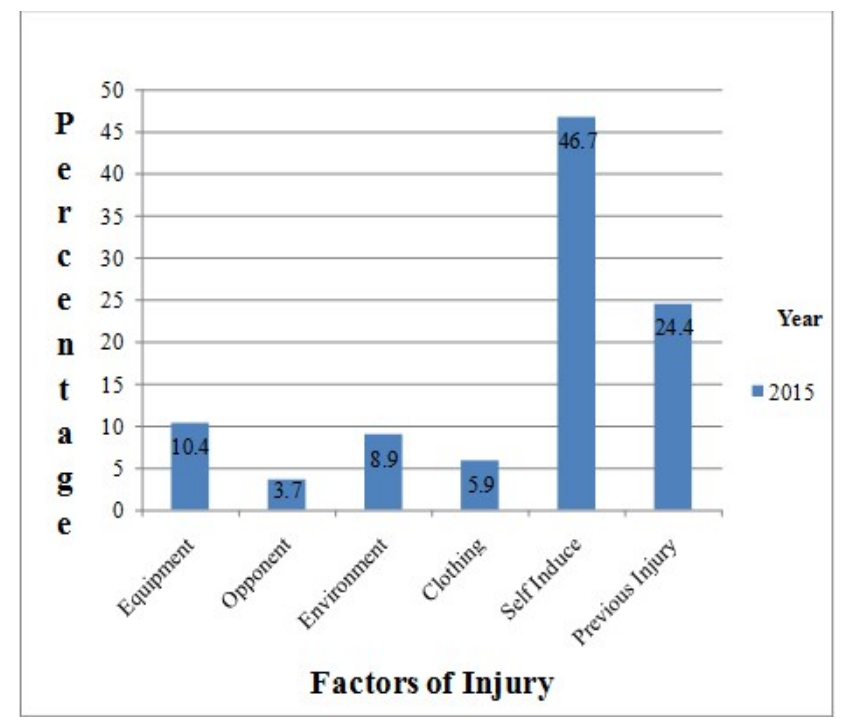

Fig.5. Percentage distribution of factors of injury

According to Meeuwisse, many factors are known or suspected to modify the risk or likelihood that an athlete will get injured during training or competition in sports and recreational physical activity [21]. Mostly the injuries happened during non-contact sports were due to neuromuscular fatigue, immaturity musculoskeletal and physiological system of athletes. The changing trend of the game from a game of fitness to high risk sports also known as one of the factors contributing to injuries. This study is reported that most injuries in non-contact sports were chronic injury that due to training volume. The chronic injury was caused by repeated micro trauma over time. The repetitive stress on the body part is damaging the tissues as the resting period is not included during training or competition sessions. Most of the injuries for athletics are shin splints. Shin splints were caused by repetitive stress on the shinbone and the connective tissues that attach muscles to the bone [22]. Fiore et al., found that athletes in white water kayaking also appeared to be injured more often on rapids or if their skill is not up to the standard [23]. Poor techniques of paddling would be expected to have the greatest impact on chronic injuries such as tendinitis impact injuries. Too much movements or repetitive movement, the increase of cardiovascular and muscle stress, the increase of water exposure, and lack of resting time could cause the injuries among the paddlers. The paddlers need enough recovery periods to be adapting all the risk of factors. Thus, the coaches and athletes should be aware on training volume and make sure have 
enough resting time after training. Athletes' insufficient techniques should be corrected by qualified coaches because wrong techniques may be as possible risk factors of injuries.

\section{CONCLUSION}

This study findings were essential for sport therapist, physiotherapy, medical doctors and related sports personnel because it could provide useful information before developing injury prevention strategy, appropriate treatment and rehabilitation program with the consideration of degree of injury, common injury type, injury risk factors and location of the injury. It is also providing the rehabilitation team more accurate injury information so that they could focus on appropriate rehabilitation plan, thus helping the injured athletes to return to play safely in shorter time. The coaches and athletes could benefit from this study by referring the risk factors and taking necessary actions in preventing injuries occurred. In conclusion, supervision and monitoring athletes during training is essential by all the sports community to minimize the risk of injury.

\section{ACKNOWLEDGEMENTS}

This research is funded by the Research Management and Innovation Centre (RMIC) of Universiti Pendidikan Sultan Idris, Perak, Malaysia.

\section{REFERENCES}

[1] Shirley D, Finch C. Relationship between adolescent sports injuries, intensity of sports participation and age. "From Cell to Society" $4^{\text {th }}$ College of Health Science Research Conf, 2004

[2] Murphy D F, Connolly D A, Beynnon B D. Risk factors for lower extremity: A review of the literature. British J. Sports Med., 2003, 37:13-29

[3] Hagglund M, Walden M, Ekstrand J. Previous injury as a risk factor for injury in elite football: A prospective study over two consecutive seasons. British J. of Sports Med., 2006, 40:767-772

[4] Keays G, Swaine B, Feldman D E. Association between severity of musculoskeletal injury and risk of subsequent injury in children and adolescents on the basis of parental recall. 
Achieves Paediatric Adolescent Med., 160:812-816

[5] Verhangen E A, Van Der Beek, Bouter L M, Bahr R M, Van Mechelen W. A one season prospective cohort of study of volleyball injuries. British J. of Sports Med., 2004. 38:477-481

[6] Schwebel D C, Banaszek M M, McDaniel M. Brief reports: Behavioral risk factors for youth soccer (football) injury. J. of Ped.Pysch, 2007, 32

[7] Gosling C M, Forbes A B, McGiven J, Gabbe B J. A profile of injuries in athletes seeking treatment during a triathlon race series. American J. of Sports. Med, 2010, 38:1007-1014

[8] Rauth M J, Macera C A, Ji M, Wiksten D L. Subsequent injury patterns in girls' high school sports. J. of Athletic Training, 2007, 42:486-494

[9] Hootman J M, Dick R, Agel J. Epidemiology of collegiate injuries for 15 sports: Summary and recommendations for injury prevention initiative. J. of Athletic Training 2007, 42:311-319 [10] Fernandez W G, Yard E E and Comstock R D. Epidemiology of lower extremity injuries among United State high school athletes. Academic Emergency Medicine, 2007, 14:641-645

[11] Shields B J, Smith G A. Cheerleading-related injuries to children 5-18 years of age: United States 1990-2002. American Academy of Pediatrics, 2006, 117:122-129

[12] Arendt E, Agel J, Dick R. Anterior cruciate ligament injury patterns among collegiate men and women. J. of Athletic Training, 1999, 34:86-92

[13] Tsui C T, Leung M, Chow C P, Chan K H, Lit A C. A one year hospital based analysis of sports injuries. Hong Kong J. of Emergency Med., 2007, 14:204-214

[14] Surve I, Schwellnus M P, Noakes T, Lombard C. A fivefold reduction in the incidence of recurrent ankle sprains in soccer players using the sports stir-up orthosis. American J. of Sports Med, 1994, 22:601-606

[15] Meyer L, Niekerk L V, Prinsloo E, Steenkamp M, Louw Q. Prevalance of musculoskeletal injuries among adolescent squash players in the Western Cape. South African J. of Sports Med., 2007, 19:3-8

[16] d'Hemecourt P. Overuse injuries in the young athlete. Acta Pediatric, 2009, 98:1727-1728

[17] Singh A, Srivastava R N. Overuse injuries in children and adolescents. Int. J. of Medical Update, 2008, 3

[18] Emery C A. Risk factors for injury in child and adolescent sport: A systematic review of 
literature. Clinical J. Sports Med., 2003, 13:256-268

[19]Dompier T P, Powell J W, Barron M J, Moore M T. Time-loss and no time-loss injuries in youth football player. J. of Athletic Training, 2007, 42:256-268

[20] Outerbridge A R, Micheli L J. Adolescent sports medicine: Changing patterns of injury in the young athletes. Sports Medicine and Arthroscopy Review, 1996, 4:93-97

[21] Meeuwisse W H. Assessing causation in sport injury: A multifactiorial model. Clinical J.of Sport Med.,1994.

[22] Cibulka M T, Sinacore D R, Mueller M J. Shin splints and forefoot contact running: a case report. J. Orthop. Sports Phy. Therapy, 20:98-102

[23] Fiore D C, Houston J D. Injuries in whitewater kayaking. British J. of Sports Med., 2001, $35: 235-241$

\section{How to cite this article:}

Lee A. C, Mohansundar S, Mondam S. and Kuang P. F. Injury profile of non-contact sports for Perak SUKMA athletes. J. Fundam. Appl. Sci., 2017, 9(6S), 1141-1151. 